\title{
Árboles del Valle Central de Costa Rica: reproducción del Güísaro (Psidium guineense Sw.)
}

\section{Trees of the Central Valley of Costa Rica: reproduction of Güísaro (Psidium guineense Sw.)}

\author{
Freddy Rojas-Rodríguez • Gustavo Torres-Córdoba²
}

\section{Resumen}

Se presenta una breve descripción del árbol de Güísaro (Psidium guineense Sw.), incluyendo información sobre fenología como base para la recolección de frutos, el manejo de las semillas, la viverización y el proceso de germinación.

Palabras clave: Fenología, manejo de semillas, viverización, germinación, árboles.

\section{Abstract}

The following issue presents a brief description about the "Güísaro" (Psidium guineense Sw), including information about its phenology which directly relates to fruit recollection, seed treatment, nursery, and germination processes.

Keywords: Phenology, seeds treatments, management at nursery, germination.

1. Consultor Independiente; Cartago, Costa Rica; freddyrojasrodriguez@gmail.com

2. Tecnológico de Costa Rica, Escuela de Ingeniería Forestal;

Cartago, Costa Rica; gtorres@tec.ac.cr; (+506) 2550- 2039
Recibido: 29/04/2019

Aceptado: 24/05/2019

Publicado: 28/06/2019

DOI: $10.18845 /$ rfmk.v16i39.4440 


\section{Taxonomía}

Nombre científico: Psidium guineense Sw.

Nombre común: Güísaro, guayabito sabanero.

Familia: Myrtaceae.

Origen: Nativa.

Distribución en el mundo: América tropical, propio de pastizales, matorrales, terrenos áridos y rocosos, desde México hasta Brasil.

Distribución en Costa Rica: Frecuentemente en potreros y sitios abandonados, especialmente en la Región Central [1].

\section{Descripción}

Árbol pequeño (tipo arbusto), de copa umbeliforme amplia, rala, en capas y con ramas colgantes. Su fuste es ramificado y en ejes múltiples desde la base. La corteza es lisa, papirácea, desprendible en placas grandes, que al caer su fuste se aprecia de color café cremoso pálido. Esta especie, según Geilfus [2], también se puede reproducir por medio de brotes de raíz.

Las hojas son simples, opuestas, de forma variable, de 10 a $15 \mathrm{~cm}$ de largo y de 4 a $6 \mathrm{~cm}$ de ancho, con envés ferrugíneo y pubescente, con nervaduras prominentes. Presenta inflorescencias blancas con estambres numerosos y desiguales.

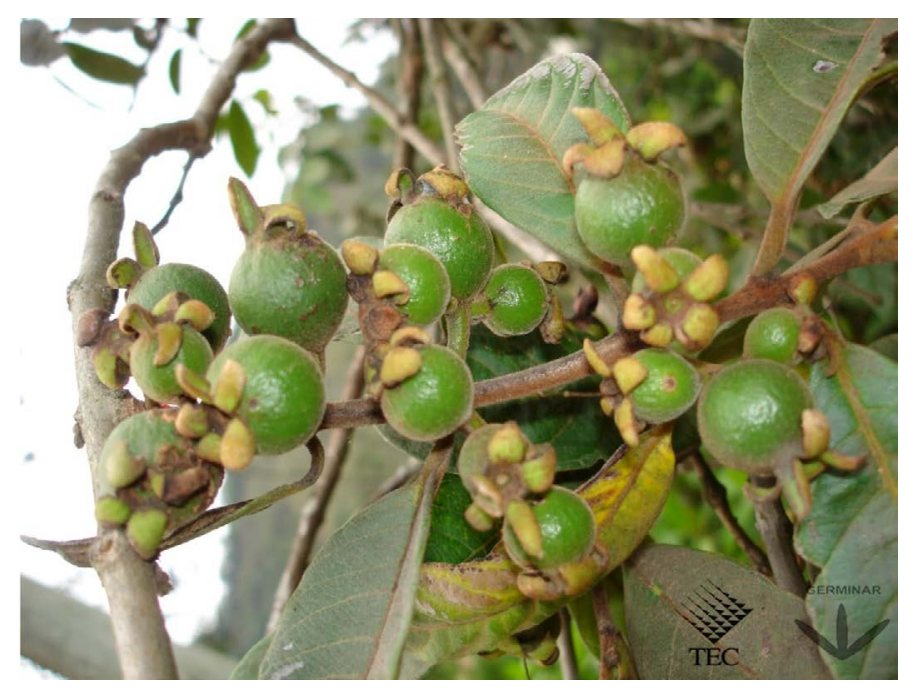

Figura 1. Fruto de Güísaro.

Figure 1. Fruit of "Güísaro" tree.
Cuadro 1. Dendrofenocronograma del Güísaro, en el Valle Central, Costa Rica.

Table 1. Tree phenology through time in "Güísaro, ", Central Valley, Costa Rica.

\begin{tabular}{|c|c|c|c|c|c|c|c|c|c|c|c|c|}
\hline \multirow{2}{*}{ Características } & \multicolumn{12}{|c|}{ Meses del año } \\
\hline & $\mathrm{E}$ & $\mathrm{F}$ & M & A & M & J & J & A & $S$ & $\mathrm{O}$ & $\mathrm{N}$ & D \\
\hline Hojas & & & & & & & & & & & & \\
\hline Flores & & & & & & & & & & & & \\
\hline Frutos verdes & & & & & & & & & & & & \\
\hline Frutos maduros & & & & & & & & & & & & \\
\hline
\end{tabular}

\section{Dendrofenocronograma}

En el Cuadro 1 se presenta a continuación información fenológica de gravilia en el Valle Central de Costa Rica. El fruto es carnoso tipo baya, de forma globosa o redondeada, color verde amarillento al madurar, de 2 a $4 \mathrm{~cm}$ de largo y de 2 a $3 \mathrm{~cm}$ de ancho. Contiene una pulpa de olor y sabor agradable, amarillenta y con numerosas semillas. Las semillas, tipo microspermas, son pequeñas aplastadas, duras y de coloración amarilla. De testa gruesa y de 2,0 mm de largo y $1,5 \mathrm{~mm}$ de ancho [3].

\section{Manejo de semilla y viverización}

Los frutos tipo baya de güisaro se recolectan en los meses de agosto a noviembre en el Valle Central de Costa Rica. La madurez de sus frutos se reconoce por su color oscuro y momento de dispersión especialmente de tipo barócora. La recolección preferiblemente debe hacerse directamente del suelo [3].

Las semillas se deben procesar en una licuadora a baja velocidad y con agua abundante se logra obtener semillas limpias. Estas en caso de ser almacenadas se recomienda sea en cuarto frío, a una temperatura de $3-10{ }^{\circ} \mathrm{C}$, una humedad relativa de $10 \%$ y en bolsas selladas herméticamente. Estas se siembran por el método del voleo en un sustrato a base de tierra más arena y se deben cubrir apenas superficialmente, siendo que la germinación se experimenta entre 12-25 días después de la siembra. Su porcentaje de germinación, dependiendo de la calidad de la semilla, varía de un 60$84 \%$ y se puede llegar a obtener un total de 104018 semillas por kilo [3].

Las plántulas se encuentran listas para su repique o trasplante, bajo el sistema de producción en bolsa plástica o pote biodegradable tres semanas posteriores 


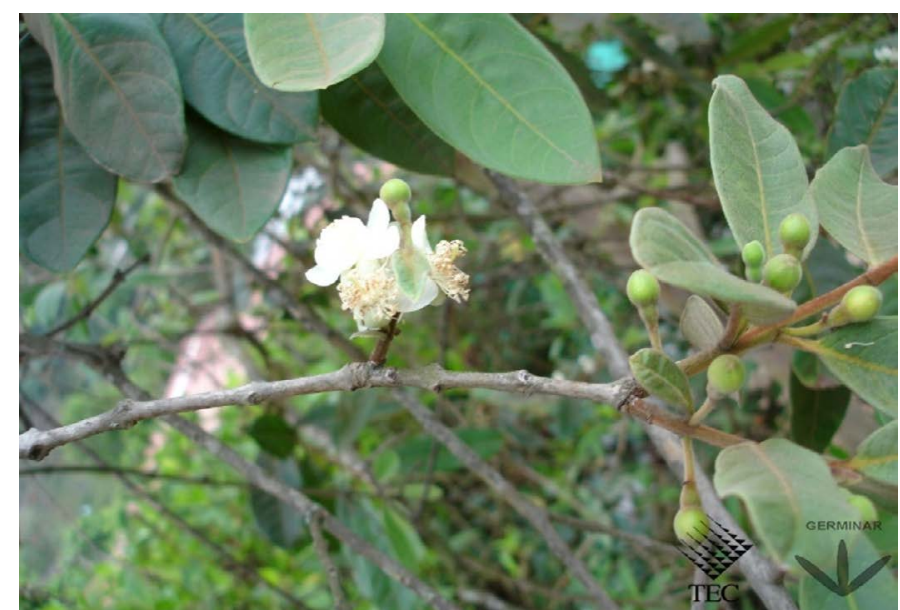

Figura 2. Flor de Güísaro.

Figure 2. Flower of "Güísaro" tree.

a la germinación. En cuanto al mantenimiento, no es recomendable aplicar sombra por un periodo no mayor a los 8 días, y se recomienda incorporar en el sustrato, fertilización química u orgánica [3].

\section{Proceso de germinación}

El tipo de germinación del guácimo ternero es epígea, según la figura 3.

\section{Referencias}

[1] León, J. y Poveda, L. (2000). Los nombres comunes de las plantas en Costa Rica. (Ed.) Pablo Sanchez. Editorial Guayacán: San José, Costa Rica. p 307.



Figure 3. Proceso de germinación del Guácimo tierno.

Figure 3. Seed germination of "Guácimo tierno" tree.
[2] Geilfus, F. El árbol al servicio del agricultor: Manual agroforestal para el desarrollo rural. Enda-Caribe, CATIE. Santo Domingo, República Dominicana. 1989. 167p.

[3] Torres, C., Carvajal, D., Rojas, F. y Arguedas M. Reproducción de especies arbóreas y arbustivas de la región central de Costa Rica (Germinar 2.0). Cartago, Costa Rica: Instituto Tecnológico de Costa Rica. Recuperado de: https:// www.tec.ac.cr/sites/default/files/media/swf/Germinar_2/ Germinar-2.swf. 2011 